This document is the accepted manuscript version of the following article:

Hu, Z., Hilaire, A., Wyrzykowski, M., Lura, P., \& Scrivener, K. (2020). Visco-elastic behavior of blended cement pastes at early ages. Cement and concrete composites, 107, 103497 (12 pp.). https://doi.org/10.1016/j.cemconcomp. 2019.103497

This manuscript version is made available under the CC-BY-NC-ND 4.0 1icense http:// creativecommons.org/1icenses/by-nc-nd/4.0/

Hu, Z., Hilaire, A., Wyrzykowski, M., Lura, P. and Scrivener, K., 2019. Visco-elastic behavior of blended cement pastes at early ages. Cement and Concrete Composites, p.103497.

\title{
Visco-elastic behavior of blended cement pastes at early ages
}

\author{
Zhangli $\mathrm{Hu}^{1 *}$, Adrien Hilaire ${ }^{2}$, Mateusz Wyrzykowski ${ }^{1}$, Pietro Lura ${ }^{1,3}$, Karen Scrivener ${ }^{4}$ \\ ${ }^{1}$ Empa, Swiss Federal Laboratories for Materials Testing and Research, Dübendorf CH-8600, Switzerland \\ ${ }^{2}$ GEOTEST AG, Zollikofen CH-3052, Switzerland \\ ${ }^{3}$ Institute for Building Materials, ETH Zurich, Zurich CH-8092, Switzerland \\ ${ }^{4}$ Laboratory of Construction Materials, Ecole Polytechnique Fédérale de Lausanne (EPFL), Lausanne CH- \\ 1015, Switzerland
}

\begin{abstract}
:
This study aims at elucidating the visco-elastic behavior of hardening blended cement pastes, focusing on uniaxial basic compressive creep tests at early loading ages. Cement pastes with Portland cement only or blended with quartz or fly ash (both at a substitution level of $49 \%$ by volume of the total solids) were subjected to different loading scenarios.

The results show that both blended systems had higher creep than pure cement paste at early ages and that the creep compliance of the blended system with fly ash was higher than with quartz. While this difference is in part due to the restraining effect of the elastic phases, the amount of C-S-H and the porosity, dissolution creep may also play a role. A numerical algorithm with generalized Kelvin-Voigt chain model was developed and it was capable of predicting with good accuracy the strain evolution of the blended cementitious materials at early ages.
\end{abstract}

Keywords: visco-elastic behavior; blended systems; microstructure evolution; Kelvin-Voigt models; aging

\section{Introduction}

Creep of concrete is of utmost importance in engineering practice, constituting at the same time a vivid scientific question [1]. On the one hand, the visco-elastic response has a substantial impact on the evolution of restraint stresses (manifesting as stress relaxation) and therefore cracking, in particular at early ages [2]. On the other hand, it may lead to substantial deformations of concrete members in the long term [3]. Another important consequence of the visco-elastic behavior is the loss of prestress in prestressed concrete elements and structures [4,5].

Because of the unclear acting mechanisms and the possible coupling between moisture-induced and loadinduced deformations, only few fundamental investigations are available in the literature about creep at early ages, e.g. [6]. A particular challenge in experimental isolating of the basic mechanisms at early ages is the rapid progress of hydration, which causes volume increase of load-bearing hydration products [7,8] and rapid, parallel increase of the elastic properties [9]. The evolution of creep properties caused by the evolution of the microstructure, while under load, is referred to as the creep aging [7,10]. Further

\footnotetext{
${ }^{1}$ Corresponding author: zhangli.hu@empa.ch, Tel +41-216932821, Fax +41-216933752
} 
complexity emerges for microstructures where pure cement is blended with supplementary cementitious materials (SCM).

This paper focuses in particular on the uniaxial compressive creep at early ages measured in sealed conditions, i.e. basic creep. Basic creep of cementitious materials has been found to depend on a large number of factors, e.g. mixture design such as water to cement ratio $(\mathrm{w} / \mathrm{c})$, mineral admixtures, temperature, type of loading, loading duration, loading ages $[2-4,6]$.

The effect of supplementary cementitious materials (SCM) on early-age creep still needs to be studied systematically. One prominent example of SCM commonly used is fly ash [11-13]. In [14], a slight increase of specific creep in tension and in compression was observed when the fly ash content in concrete was increased from about $17 \%$ to $33 \%$ (by mass of binder). Negligible changes in creep were reported for fly ash replacements up to $15 \%$, and a slight increase for higher replacement ratios in [15]. On the other hand, fly ash addition in concrete has been reported in [16] (and in other studies carried out in China cited in that paper) to lead to a reduction of creep. Similar conclusions were drawn in [17], in which reduction of creep in concretes with fly ash and slag was explained as an effect of low reactivity of the SCMs, leading to their acting as fine aggregates that restrain creep strains. These contradicting trends in the behavior of cement with fly ash were partly attributed to the type of fly ash used in different studies [18].

In this paper, an experimental study about basic creep at early ages of cement pastes with or without fly ash (class F) is presented. Most of the studies about creep in the literature are on concretes [14,16,17], in which however the purely elastic response of the aggregates reduces the overall visco-elastic response. Therefore, to investigate the effect of fly ash on creep of the matrix, cement paste was employed in this study. Additionally, systems with quartz powder blended with cement are used. Using inert quartz powder in the model systems (with the same volume as the fly ash in the fly ash systems) enables distinguishing the effect of the (pozzolanic) reaction of fly ash from the mere filler effect.

Uniaxial creep in compression was measured at different loading ages from $20 \mathrm{~h}$ to $14 \mathrm{~d}$, both using separate loading/unloading cycles and sequential loading (with load gradually increased at different ages). The observed creep results, in particular the differences caused by using SCM, are discussed in terms of differences in hydration products (studied with X-ray diffraction) and porosity (studied with mercury intrusion porosimetry, MIP).

\section{Rheology models (Kelvin-Voigt model) for predicting creep of cement pastes under step-wise loading}

Since the driving mechanism of creep is unclear and fundamental tests are missing, modelling of creep and creep recovery remains extremely challenging. The most challenging part in modelling creep at early ages is aging, i.e. evolution of material (creep) properties while under load. Another complexity emerges when load changes. This is the case e.g. when load is updated in laboratory tests to match the evolving mechanical properties (i.e. constant stress-strength ratio), or when internal load due to drying or selfdesiccation evolves in the pores causing corresponding changes of effective stress acting on the skeleton.

Linear viscoelasticity models are most commonly used for the description of creep of cement-based materials, e.g. [10,19-22]. In these models, based on a linear stress-strain relationship, the superposition principle is used and the creep compliance is independent of the applied stress. Creep linearity is also assumed in this work. 
The viscoelastic compliance can be mathematically described using different rheology models, e.g. Maxwell or Kelvin-Voigt chains [10,19-22]. For describing aging creep at the macroscopic scale due to the evolution of the underlying microstructure, the properties of the assumed chain elements (springs and dashpots) evolve in time [20], for example with the degree of hydration [10,23-25]. The parameters of the rheology models are usually obtained by numerical fit of the experimental macroscopic creep data.

In this paper, a rheology model, in particular a generalized age-dependent (via hydration degree) KelvinVoigt chain (see e.g. [20]), Fig.1, was used to predict the trend of aging creep under sequential loading. The rheology model used in this study has evolving spring stiffness and dashpot viscosities units that both depend on either loading time or degree of hydration to introduce the age or time dependency [26]. It should be noted that these models are only mathematical approximations of the visco-elastic behavior and they do not attempt to simulate the actual chemical or physical processes acting in the materials. Nevertheless, some work has been done to identify the elastic constants and the visco-elastic response of the different components in the cement paste, in order to link the phases properties and the modeling parameters together, giving a physical meaning to the model [20]. In [20], the parameters in the KelvinVoigt model were related to the interfacial density, interfacial radii and interfacial viscosities. In this study, the parameters of the Kelvin-Voigt chain are calibrated with the creep data under constant loads and verified for the same system but with different loading scenario - stepwise loading.

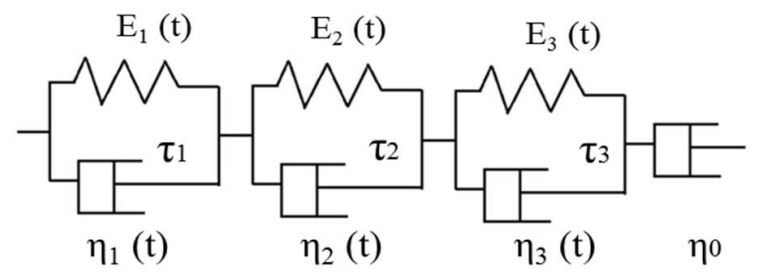

Fig.1 Schematic representation of the generalized Kelvin-Voigt model.

As seen in Fig.1, the generalized Kelvin-Voigt model employed in this paper is composed of three KelvinVoigt units and an additional dashpot in series. The number of Kelvin-Voigt units is selected for better capturing the creep evolution but does not need to be a unique value, e.g. three. The Kelvin-Voigt units can be used to model the short-term mechanism, e.g., due to micro-diffusion [27-29]; the additional dashpot represents the long-term mechanism, e.g., the sliding of the C-S-H [30], which is proportional to time in the model. The coefficients in the model are defined as follows: $E_{n}(t)[\mathrm{MPa}]$ are the aging moduli of the springs in the individual Kelvin-Voigt unit, with $n 1$ to $3 ; t$ is time [day]; $\eta_{n}(t)$ [MPa] are the viscosities of the dashpots in the corresponding Kelvin-Voigt units. The additional dashpot has viscosity $\eta_{0} . \tau_{n}[$ day $]$ are the characteristic times.

For each Kelvin-Voigt unit, a set of governing equations are presented as follows:

$$
\begin{aligned}
& \dot{\varepsilon}_{n}=\frac{\sigma_{n \eta}}{\eta_{n}(t)} \\
& \dot{\varepsilon}_{n}=\frac{\dot{\sigma}_{n}-\dot{\sigma}_{n \eta}}{E_{n}(t)}
\end{aligned}
$$

where $\varepsilon_{n}$ is the strain in each Kelvin-Voigt unit; $\sigma_{n}$ and $\sigma_{n \eta}$ are the stresses in the Kelvin-Voigt units (equal to the applied stress) and in each dashpot, respectively. 
With the relationship between the viscosity of the dashpot and the stiffness of the spring: $\eta_{n}(t)=E_{n}(t) \times \tau_{n}$ and a constant characteristic time for each Kelvin-Voigt unit, Eq. (1) and Eq. (2) can be transformed into a second-order differential equation:

$$
\tau_{n} \cdot \ddot{\varepsilon}_{n}+\left(1+\frac{\dot{E}_{n}(t)}{E_{n}(t)} \cdot \tau_{n}\right) \cdot \dot{\varepsilon}_{n}=\frac{\dot{\sigma}_{n}}{E_{n}(t)}
$$

With this equation, the stress and strain in each individual Kelvin-Voigt unit at each time step can be linked together. A numerical algorithm for incremental strain calculation embedded in the generalized Kelvin-Voigt model, following the method in [25], results in Eq.(4). The stress in the dashpot is updated at each discretized time step $i$, see Eq.(5). The whole numerical schematic flow chart for an individual Kelvin-Voigt unit is presented in Fig.2. With the deformation of the additional dashpot $\varepsilon_{a m}$, the total strain $\varepsilon_{b c}$ can be calculated. The expression used to calculate $\varepsilon_{a m}$ is shown in Eq.(6), as a function of the viscosity of the dashpot at infinite time $\eta_{\infty}$, the degree of hydration $\alpha$ and initial porosity $p_{0}$. In Eq.(6), the volume of the anhydrous phases was calculated as $\left(1-p_{0}\right) \cdot(1-\alpha)$, according to Powers' model [31]. The expression was verified in creep models in different studies, see [32]. In this study, the parameters of the rheology model are calibrated with creep results of specimens under constant loads and verified by predicting the creep results under stepwise loading.

$$
\Delta \varepsilon_{n}^{i}=\frac{\sigma_{n}^{i}}{k_{n}^{i}} \cdot\left(1-e^{-\frac{\Delta t_{i}}{\bar{t}_{n}^{i}}}\right)+\left(\sigma_{n}^{i+1}-\sigma_{n}^{i}\right) \cdot \frac{1}{k_{n}^{i}} \cdot\left(1-\frac{\eta_{n}^{i}}{k_{n}^{i} \cdot \Delta t_{i}} \cdot\left(1-e^{-\frac{\Delta t_{i}}{\bar{t}_{n}^{i}}}\right)\right)
$$

where $k_{n}$ is equal to $E_{n}+\dot{E}_{n} \times \tau_{n}$ and $\bar{\tau}_{n}$ equal to $\tau_{n} /\left(1+\dot{E}_{n} /\left(E_{n} \cdot \tau_{n}\right)\right)$

$$
\begin{array}{r}
\sigma_{n}^{i+1}=\eta_{n}^{i+1} \cdot\left(\frac{\sigma_{n \eta}^{i}}{\eta_{n}^{i}} \cdot\left(1-\frac{k_{n}^{i} \cdot \Delta t_{i}}{E_{n}^{i} \cdot t_{n}^{i}}\right)+\frac{\dot{\sigma}_{n}^{i}}{\eta_{n}^{i}} \cdot \Delta t_{i}\right) \\
\Delta \varepsilon_{a m}=\frac{\sigma_{n}^{i+1}+\sigma_{n}^{i}}{2} \cdot \ln \left(\frac{t_{i+1}}{t_{i}}\right) /\left(\frac{\eta_{\infty}}{1-\sqrt{\left(1-p_{0}\right) \cdot(1-\alpha)}}\right)
\end{array}
$$

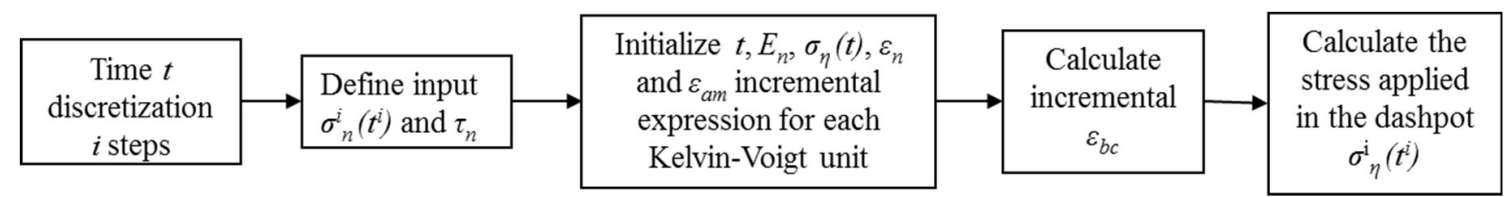

Fig.2 Numerical scheme for calculating the strain increment in the Kelvin-Voigt model.

\section{Materials and methods}

Ordinary Portland cement CEM I 42.5R (Holcim), quartz powder and class F fly ash with density of 3.12 $\mathrm{g} / \mathrm{cm}^{3}, 2.67 \mathrm{~g} / \mathrm{cm}^{3}$ and $2.17 \mathrm{~g} / \mathrm{cm}^{3}$, respectively, were used in this study. Cement, fly ash and quartz fillers have mean diameters of about 13,16 and $12 \mu \mathrm{m}$, respectively. The oxide compositions of the materials are listed in Table 1. The mineral phases of cement quantified with X-ray diffraction and Rietveld analysis are $^{2}$ : $69 \% \mathrm{C}_{3} \mathrm{~S}, 8.3 \% \mathrm{C}_{2} \mathrm{~S}, 6.7 \% \mathrm{C}_{3} \mathrm{~A}$ and $8.2 \% \mathrm{C}_{4} \mathrm{AF}$. Pastes of pure cement (PC), cement blended with

${ }^{2} \mathrm{C}_{3} \mathrm{~S}$ stands for $3 \mathrm{CaO} \cdot \mathrm{SiO}_{2}, \mathrm{C}_{2} \mathrm{~S}$ stands for $2 \mathrm{CaO} \cdot \mathrm{SiO}_{2}, \mathrm{C}_{3} \mathrm{~A}$ stands for $3 \mathrm{CaO} \cdot \mathrm{Al}_{2} \mathrm{O}_{3}$ and $\mathrm{C}_{4} \mathrm{AF}$ stands for $4 \mathrm{CaO} \cdot \mathrm{Al}_{2} \mathrm{O}_{3} \cdot \mathrm{Fe}_{2} \mathrm{O}_{3}$ 
$40 \%$ by mass fly ash (49\% of volume replacement of cement by fly ash, CFA 40 ) and cement blended with $46.7 \%$ by mass of quartz ( $49 \%$ volume replacement of cement by quartz, CQZ40) with the same water-to-solid ratio of 0.35 were prepared. Mixing was done with a vacuum mixer with mixing speed of $450 \mathrm{rpm}$ for $2 \mathrm{~min}$.

Table 1 Chemical compositions of materials used in $\%$ by mass

\begin{tabular}{ccccccccccccc}
\hline Powder & $\mathrm{SiO}_{2}$ & $\mathrm{Al}_{2} \mathrm{O}_{3}$ & $\mathrm{Fe}_{2} \mathrm{O}_{3}$ & $\mathrm{CaO}$ & $\mathrm{MgO}$ & $\mathrm{SO}_{3}$ & $\mathrm{Na}_{2} \mathrm{O}$ & $\mathrm{K}_{2} \mathrm{O}$ & $\mathrm{TiO}_{2}$ & $\mathrm{P}_{2} \mathrm{O}_{5}$ & $\mathrm{Mn}_{2} \mathrm{O}_{3}$ & L.O.I \\
\hline cement & 20.45 & 4.39 & 3.01 & 64.48 & 1.66 & 2.83 & 0.24 & 0.89 & 0.34 & 0.28 & 0.05 & 1.3 \\
fly ash & 69.67 & 23.8 & 2.39 & 0.1 & 0.2 & 0.01 & 0.09 & 0.61 & 1.51 & 0.14 & 0.05 & 0.95 \\
quartz & 99.83 & - & 0.03 & 0.02 & - & - & - & 0.05 & 0.02 & - & - & 0.02 \\
\hline
\end{tabular}

\subsection{Young's modulus}

At early ages (before $10 \mathrm{~d}$ ), the Young's modulus was measured continuously with the Elasticity Modulus Measurement through Ambient Response Method (EMM-ARM) [33] to follow the kinetics of the Young's modulus development. A hollow cylindrical beam made of acrylic glass with length of $550 \mathrm{~mm}$, outer diameter of $20 \mathrm{~mm}$ and inner diameter of $16 \mathrm{~mm}$ was used. The tubes were sealed with polypropylene caps after being filled with fresh paste and placed in a temperature-controlled room at $20 \pm 0.3{ }^{\circ} \mathrm{C}$. Then one end of the composite beam was fixed in the horizontal position with a metal clamp, forming a cantilevered with a span of $450 \mathrm{~mm}$. Afterwards, a lightweight accelerometer (mass and sensitivity equal to $23 \mathrm{~g}$ and $1 \mathrm{~V} / \mathrm{g}$, respectively) was attached to the free end of the cantilever beam. A fan was placed on one side of the beam to increase the amplitude of the vibration.

\subsection{Compressive strength test}

The compressive strength of the paste was measured to determine the stress to be applied during the creep measurements following the standard [34]. The tests were done on three specimens each at desired ages (1, 3,7 and $14 \mathrm{~d}$ ). Prismatic specimens with size of $40 \times 40 \times 160 \mathrm{~mm}^{3}$ were cast and sealed cured in a temperature-controlled chamber $\left(20 \pm 0.3{ }^{\circ} \mathrm{C}\right)$ after demolding. After one day curing, the specimens were cut into $40 \times 40 \times 40 \mathrm{~mm}^{3}$ cubic specimens with a saw using water as lubricant.

\subsection{Uniaxial compressive creep}

Uniaxial compressive creep tests were performed on pastes in creep stations using gravitational load cells. The detailed setup and a description of the method are presented in [35]. Specimen of $25 \times 25 \times 80 \mathrm{~mm}^{3}$ were cast in steel molds and demolded after $19 \mathrm{~h}$ (leaving a minimum of $1 \mathrm{~h}$ for the sample preparation before the experiments). They were sealed afterwards with polyethylene film (first layer, in contact with the sample) and self-adhesive aluminum foil (second layer, applied over the plastic film) to limit drying. The average mass loss during the experiments was less than $0.1 \%$, thus the contribution of drying was assumed negligible.

Two loading processes were applied in this study: separate loading/unloading cycles and sequential loading, named as constant loading and stepwise loading, respectively. In the stepwise loading process, the initial load was added at $20 \mathrm{~h}$ and successive loads were added onto the same sample at desired ages, increasing the applied stress to match $10 \%$ of compressive strength at the age of loading. It should be mentioned that the stepwise was applied at relatively long-time intervals (from $22 \mathrm{~h}$ to $14 \mathrm{~d}$ ), and hence aging creep was determined in between the loading steps. Such load-scheme is different from the shortterm loading (3-min loading steps) 
In the constant loading process, loads were added only once corresponding to $10 \%$ of the strength at that age and removed at desired ages on different samples. The detailed loading steps are shown in Fig. 3. It took less than $10 \mathrm{~s}$ to apply the whole load at each loading step. The data was logged at the interval of $1 \mathrm{~s}$ in the first $15 \mathrm{~min}$ during each loading step and 2 min afterwards. Two specimens were used for each loading step. The test was performed in a room at $19.8 \pm 0.3{ }^{\circ} \mathrm{C}$ and relative humidity $75.4 \% \pm 1.6 \%$.

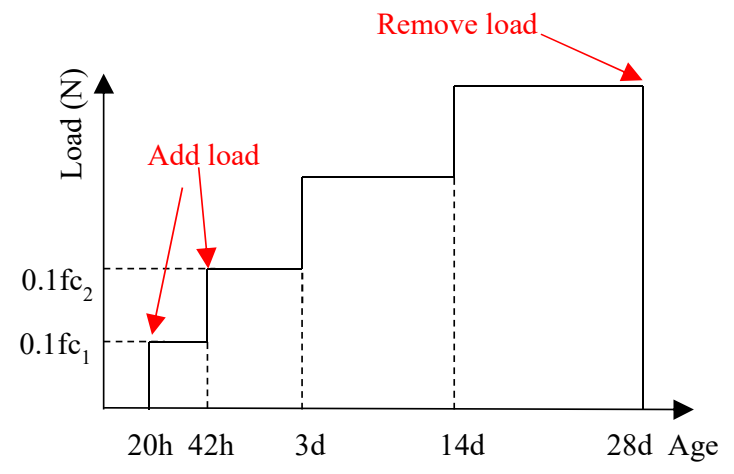

(a) Stepwise loading process

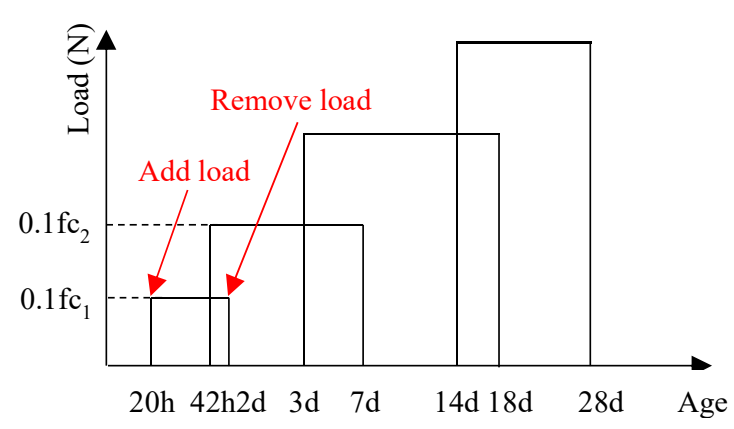

(b) Constant loading process

Fig. 3 Schematic representation of loading steps for different loading histories. In the stepwise loading process, loads were added sequentially on the same specimen; in the constant loading process, different specimens were used for each loading cycle.

\subsection{Autogenous shrinkage}

The linear autogenous shrinkage strains $\varepsilon_{a s}$ were measured with the corrugated tubes method adapted from ASTM C1698-09 [36] for automatic measurements as described in [37]. The results were subtracted from the total creep deformation $\varepsilon_{b c}$ measured on loaded samples to yield the basic creep deformation, further normalized with the applied stress $\sigma_{a}$ to yield the basic creep compliance, $J_{\text {basic }}$ :

$$
J_{b a s i c}=\frac{\varepsilon_{b c}-\varepsilon_{a s}}{\sigma_{a}}
$$

A detailed explanation of this approach can be found in [35].

\subsection{Mercury intrusion porosimetry (MIP)}

The porosity was measured by MIP at different ages with the aim of studying the impact of the reduction of porosity due to cement hydration and the pozzolanic reaction of fly-ash on the creep development. The contact angle used to calculate the pore sizes was $120^{\circ}$. A detailed explanation of the method can be found in [38].

\subsection{X-ray diffraction}

$\mathrm{X}$-ray diffraction (XRD) was performed on sliced samples at 1, 3, 7, 14 and $28 \mathrm{~d}$ to quantify the amounts of hydrated phases. After casting, the samples were sealed to avoid moisture loss during the hydration process and the temperature was controlled at $20 \pm 0.1{ }^{\circ} \mathrm{C}$. The patterns of hydrated samples were recorded using an X-ray diffractometer (CuKa radiation, $45 \mathrm{kV}, 40 \mathrm{~mA}$ ) in the scanning range 5-70 ${ }^{\circ}$. The applied testing rate was $0.02 \%$. The quantification of the phases was done with Rietveld analysis (HighScore plus software). 


\subsection{Isothermal calorimetry}

The degree of hydration used for the description of the evolution of stiffness and viscosity of the KelvinVoigt units was determined based on the isothermal calorimetry. Cement pastes were mixed externally in a vacuum mixer with a speed of $450 \mathrm{rpm}$ for $2 \mathrm{~min}$ and poured into the glass ampules with diameter of $24.9 \mathrm{~mm}$. About $10 \mathrm{~g}$ of paste per specimen was used. The ampules were immediately sealed with fitted caps and placed in the cells of the calorimeter. The degree of hydration was quantified using the cumulative heat release at a specific time divided by the ultimate heat release of only cement (i.e. neglecting the fly ash) at full hydration according to [39]. The ultimate heat release of only cement was estimated based on the reaction enthalpies and the amount of the four main clinker phases. In the calculation, the enthalpies of $517 \mathrm{~J} / \mathrm{g}, 262 \mathrm{~J} / \mathrm{g}, 1144 \mathrm{~J} / \mathrm{g}$ (only the reaction of $\mathrm{C}_{3} \mathrm{~A}$ with gypsum forming ettringite was considered) and $418 \mathrm{~J} / \mathrm{g}$ were used for $\mathrm{C}_{3} \mathrm{~S}, \mathrm{C}_{2} \mathrm{~S}, \mathrm{C}_{3} \mathrm{~A}$ and $\mathrm{C}_{4} \mathrm{AF}$, respectively.

\section{Results}

\subsection{Evolution of hydration degree, microstructure and mechanical properties}

The cumulative heat release normalized by the mass of only cement is shown in Fig.4(a). The calorimetry results were used for calculating the hydration degree (see Section 3.7), presented in Fig.4(b); these data were used in the proposed generalized Kelvin-Voigt model in Section 4.6.

(a)

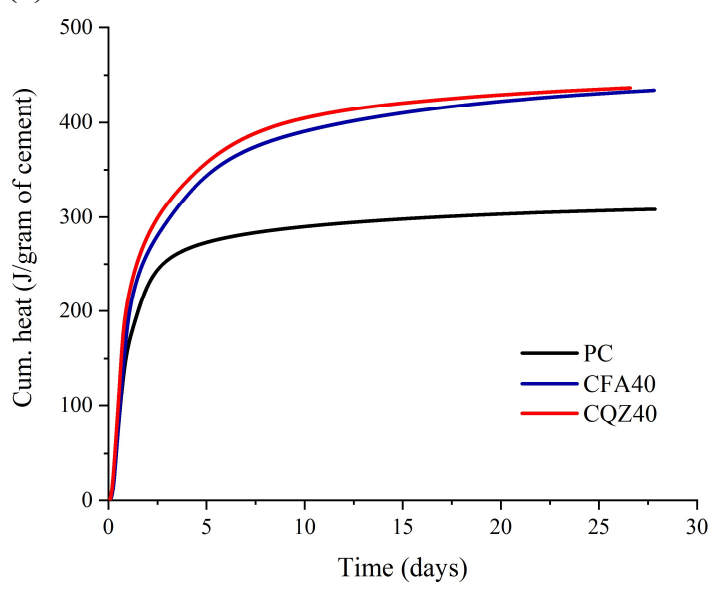

(b)

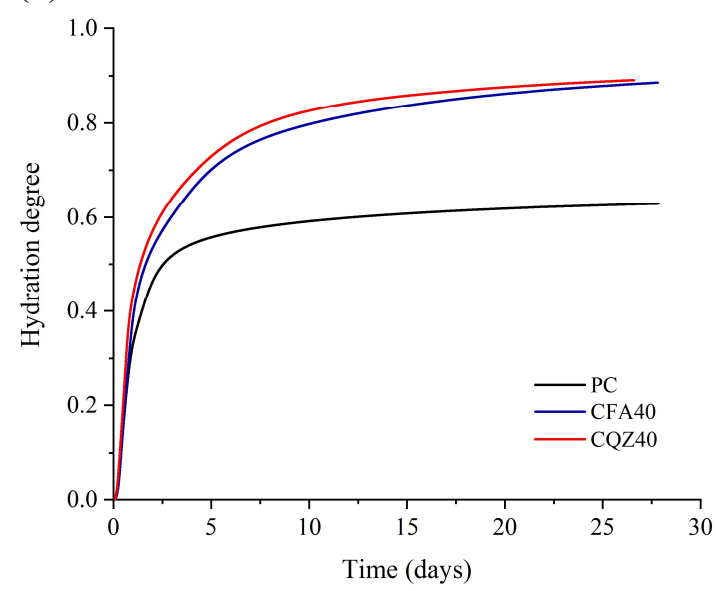

Fig. 4 Cumulative heat release normalized by the mass of cement (a); Hydration degree of the three cement pastes as a function of time (b).

Fig. 5 shows the amounts of hydration products (C-S-H and portlandite) formed in different systems as a function of time (results obtained by XRD). The systematic error of the quantification is around $5-10 \%$.

The blended systems had considerably lower volumes of C-S-H and portlandite (major hydration phases) formed. Surprisingly, the system with quartz (inert filler) had a higher volume of C-S-H formed than the system with fly ash, where in addition to the neat filler effect some increase in the volume of C-S-H, accompanied by a decrease of the volume of portlandite in the pozzolanic reaction, could be expected. However, the fly ash used in this study was examined in [40] in pastes with higher w/c and was found to 
be poorly reactive: at $14 \mathrm{~d}$, the degree of reaction of fly ash was around $10 \%$, while at $28 \mathrm{~d}$ it was around $15 \%$. Moreover, the quartz filler used here was finer than the fly ash. With higher specific surface of the filler, enhanced nucleation can be expected [41]. Additionally, the finer particles likely experienced higher shearing during mixing of the pastes, which should further lead to more nucleation sites [42]. The hydration promotion can be seen also in Fig.4 (a), which shows a slightly steeper slope of the cumulative heat release curve of CQZ40 compared to that of the other two systems. Note that the degree of hydration of PC at $28 \mathrm{~d}$ is lower than the value commonly reported in the literature (e.g. in [43] about 0.7 for cement paste with w/c of 0.35 ). The reasons can be as follows: 1) different estimation methods used; 2) cement with different composition was used. The estimation used in this study relies on the enthalpies assumed; 3 ) problems of measuring very low signal with calorimetry at later ages, leading to an underestimation of the total released heat. However, since the further calculation in Eq. (8) (see Section 4.6.1) uses the normalized degree of hydration, the exact value of the degree of hydration has limited impacts on the stiffness estimation.

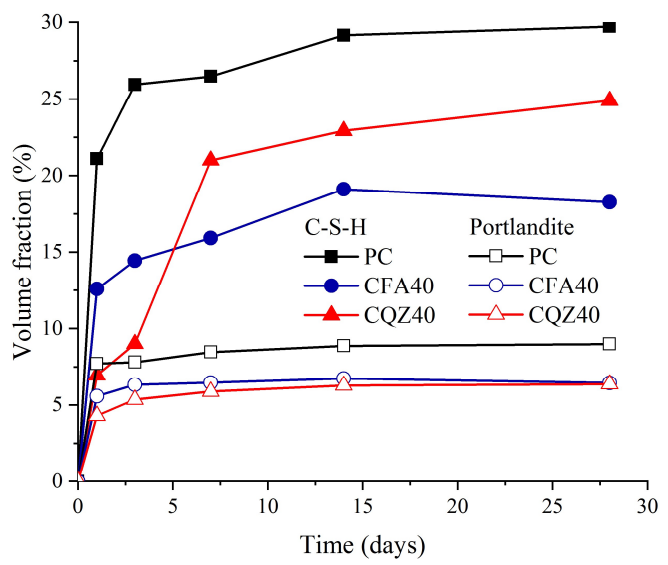

Fig. 5. XRD results showing the evolution in time of the amounts of C-S-H and portlandite in the three cement pastes.

In Fig. 6, the total MIP porosity as a function of hydration time is presented. The average standard deviation of the porosity calculated from duplicate samples is $0.5 \%$. CFA40 and CQZ40 have higher total cumulative pore volume in the first $28 \mathrm{~d}$ period than the pure cement paste, owing to a higher $\mathrm{w} / \mathrm{c}$ and smaller volume of hydration products formed; for instance, at $1 \mathrm{~d}$ the total porosity in CQZ40 is almost 1.5 times that of the pure cement paste. In PC and CQZ40, the porosity decreased rapidly during the first 3 to $7 \mathrm{~d}$ and at a slower pace afterwards. On the contrary, in CFA40 the decrease of total porosity was not very obvious in the first $3 \mathrm{~d}$ but continued steadily until $28 \mathrm{~d}$, likely because of the ongoing pozzolanic reaction. The kinetics of the porosity evolution for CFA40 and CQZ40 are in line with those of the C-S-H amount formed in the two systems, see Fig. 5. 


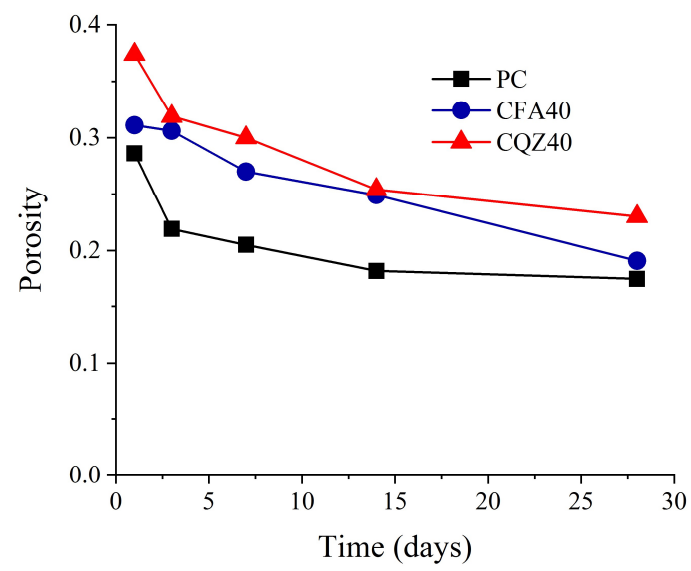

Fig. 6. Porosity evolution measured by MIP as a function of time

The results of the compressive strength tests are presented in Table 2. The replacement of cement with quartz fillers and fly ash dramatically reduced the compressive strength. This is to be expected, considering the smaller volume of hydration products (Fig. 5) and higher porosity (Fig. 6) in the blended systems. While the compressive strength of the two blended systems was almost identical up to 1 week of age, CFA40 achieved slightly higher value at later ages. This result cannot be readily explained considering that the system with quartz had still a larger volume of C-S-H at that time. On the other hand, it is very likely that the C-S-H in the system with fly ash had a lower calcium oxide to silica ratio $(\mathrm{C} / \mathrm{S})$ and consequently lower density $[44,45]$ compared to the other systems. With the lower density of the C-S$\mathrm{H}$ gel, better space filling and hence lower capillary porosity could explain the higher strength of the fly ash system compared to the quartz system.

The stress applied on different systems at different loading ages in the creep tests was calculated as $10 \%$ of the strength presented in Table 2. The strength at $20 \mathrm{~h}$ and $42 \mathrm{~h}$ was approximated as follows: at $20 \mathrm{~h} \mathrm{it}$ was found from linear interpolation between the measured value at $1 \mathrm{~d}$ and zero at casting, for $42 \mathrm{~h}$ it was a linear approximation between $1 \mathrm{~d}$ and $3 \mathrm{~d}$.

Table 2 Compressive strength results (average \pm standard deviation, triplicate samples)

\begin{tabular}{cccccccc}
\hline $\begin{array}{c}\text { Compressive } \\
\text { strength (MPa) }\end{array}$ & $\begin{array}{c}20 \mathrm{~h}- \\
\text { approx. }\end{array}$ & $1 \mathrm{~d}$ & $\begin{array}{c}42 \mathrm{~h}- \\
\text { approx. }\end{array}$ & $3 \mathrm{~d}$ & $7 \mathrm{~d}$ & $14 \mathrm{~d}$ & $28 \mathrm{~d}$ \\
\hline PC & 31.5 & $38.3 \pm 0.7$ & 45.3 & $59.3 \pm 1.4$ & $71.7 \pm 2.0$ & $84.6 \pm 2.8$ & $90.3 \pm 2.7$ \\
CFA40 & 14.9 & $16.4 \pm 1.7$ & 22.1 & $33.5 \pm 2.9$ & $46.4 \pm 1.1$ & $53.7 \pm 1.2$ & $70.3 \pm 1.4$ \\
CQZ40 & 17.5 & $18.9 \pm 0.5$ & 23.9 & $33.9 \pm 1.2$ & $44.5 \pm 2.1$ & $47.1 \pm 1.4$ & $53.6 \pm 1.0$ \\
\hline
\end{tabular}

The Young's modulus evolution measured continuously with EMM-ARM is presented in Fig. 7. In PC, the Young's modulus increased faster at early ages and reached a stable value earlier, after about $3 \mathrm{~d}$. The two blended systems had very similar evolution, with a slower increase of the Young's modulus compared to the PC system. The higher Young's modulus of PC compared to the other two systems before $7 \mathrm{~d}$ is linked with the lower porosity in PC. Interestingly, fly ash and quartz, despite having different stiffness (about 70 [46] and $72 \mathrm{GPa}$ [47], respectively) than clinker (140 GPa) in the PC system [47], to have a similar effect on the overall Young's modulus of the composite systems at the late ages considered in this study. The similar Young's modulus of CQZ40 and CFA40 (despite the higher porosity of the former) 
may be due to different morphology of hydration products, e.g. lower density of the hydration products in the system with fly ash and hence better filling $[44,45]$ or more uniform space distribution of the hydration products (and hence, again, better space filling) due to the filler effect of quartz. These morphological features could compensate for the lower stiffness of the fillers compared to that of clinker, see also [48].

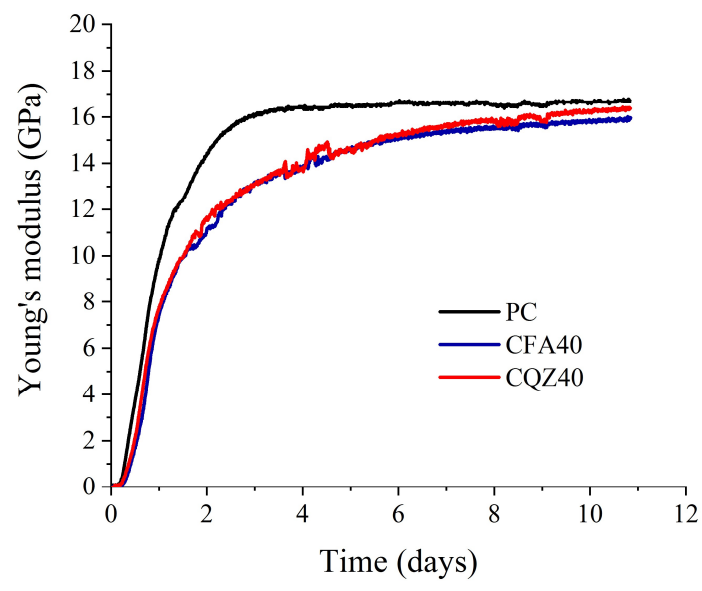

Fig.7 The evolution of the Young's modulus of the three systems measured with EMM-ARM.

\subsection{Apparent creep strain, total strain}

The measured total uniaxial strain for the three systems at different loading ages was plotted as a function of age in Fig. 8. For each measurement, the overall repeatability between two specimens was considered satisfactory in all cases. The maximum difference in total strain between duplicate samples was $7 \%$. Thanks to densely resolved data points, an initial very rapid deformation phase can be distinguished, ending several seconds after loading. It is assumed that the initial steep deformation corresponds to the instantaneous elastic deformation and it is followed by the creep deformation. It should be however noted that such distinction is only an approximation, considering that the creep deformations start immediately at the time instant of loading. Hence, as shown in the short-time creep tests by Irfan-ul-Hassan et al. [8], the initial stage necessarily includes part of the creep deformation.

(a) $\mathrm{PC}$

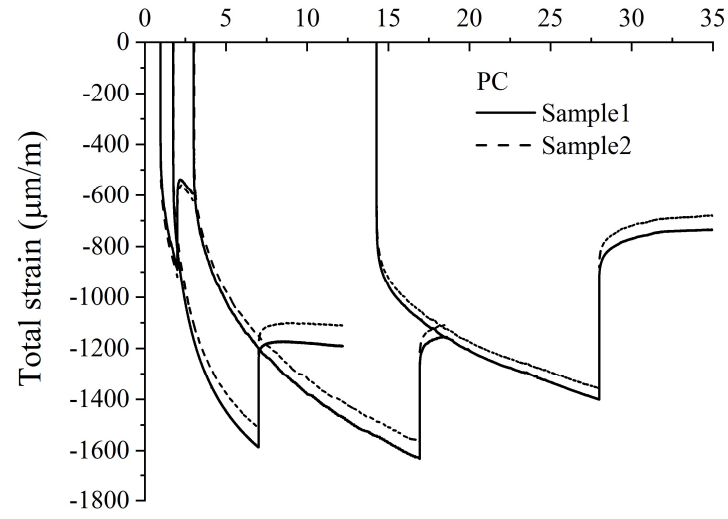

Time (days) (b) CFA40

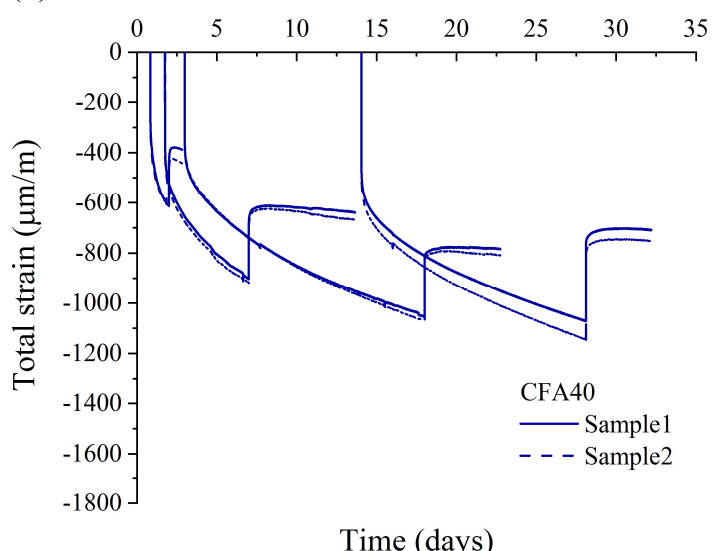

(d) Stepwise loading

(c) CQZ40 

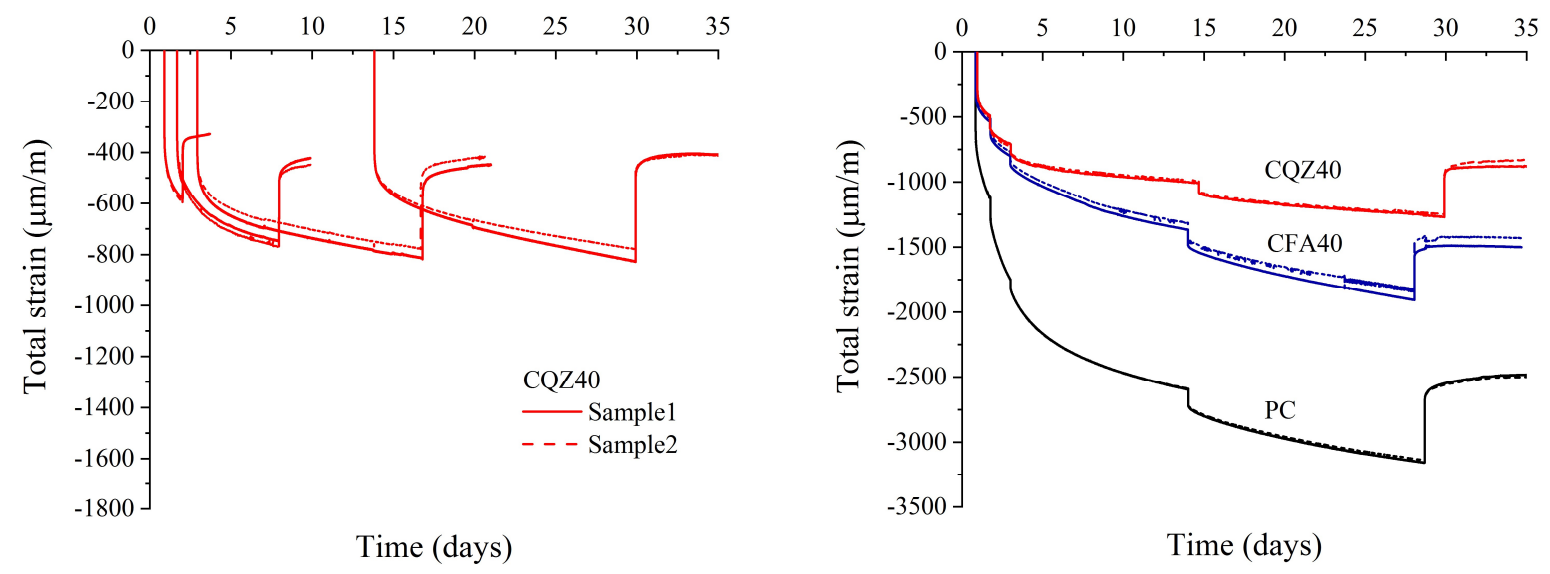

Fig. 8 Total strain (including instantaneous strain and creep strain) of different systems: (a) (b) and (c) systems under constant loading; (d) systems under stepwise loading.

The measured total uniaxial creep strain for the three systems under stepwise loading was also plotted as a function of age in Fig. 8 (d). During this loading process, the creep strain was also lower with later loading ages. It is clear from this plot that the strain evolution was gentler in CQZ40. In all systems, the creep recovery was much smaller than the creep.

The creep results presented here include the deformation due to autogenous shrinkage and are subject to differences due to different loads applied. The proper analysis is thus presented in the following sections where specific creep is shown.

\subsection{Autogenous shrinkage}

The autogenous shrinkage development of the three systems is presented in Fig. 9. The results shown here were zeroed at the time of final set (measured by Vicat needle): $6 \mathrm{~h}, 6 \mathrm{~h} 40 \mathrm{~min}$ and $6 \mathrm{~h} 45 \mathrm{~min}$ for PC, CQZ40 and CFA40, respectively.

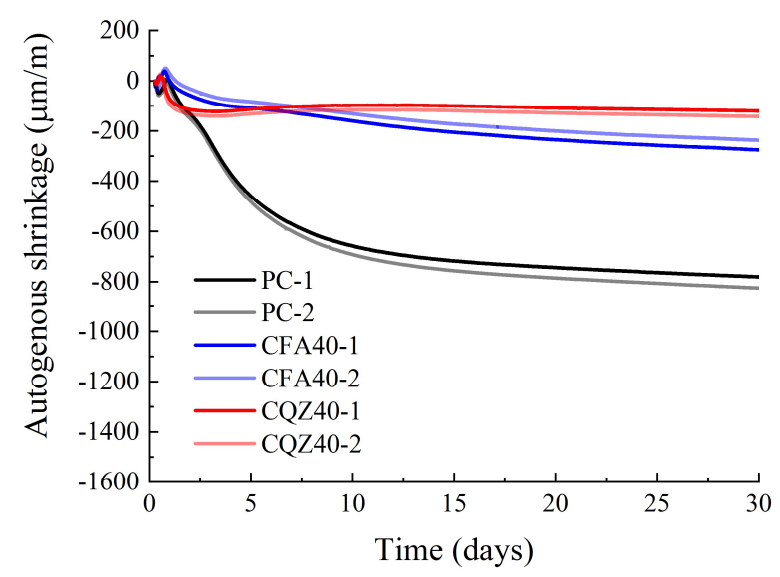

Fig.9 Autogenous shrinkage of all pastes in the first 28 days

As expected, for the total autogenous shrinkage after $28 \mathrm{~d}$, PC had the highest autogenous shrinkage because of the lower w/c. The initial faster shrinkage of the CQZ40 system compared to CFA40 system is likely due to higher fineness and therefore finer initial porosity of the quartz filler in the former system. 
Comparing pastes with the same volume fraction of either fly ash or quartz, CFA40 exhibited higher autogenous shrinkage.

\subsection{Specific basic creep compliance at different loading ages}

The basic creep compliance of the specimens, calculated according to Eq. (1) (by subtracting from the total strain (Fig. 8) the quasi-instantaneous (assumed elastic) strain and the autogenous shrinkage strain (Fig. 9)), is presented in Fig. 10. It is worth noting that the strains identified as instantaneous elastic strain corresponded very well to the quasi-static Young's modulus measurement or, more precisely, quasi-static loading moduli, see [8]) (see Appendix A).

In stepwise loading, the creep curves were separated for different periods of constant loads; the compliance was calculated by considering the total load applied on the specimen. At $20 \mathrm{~h}$ loading, the paste with fly ash had higher creep rate than the other two pastes. The differences became especially pronounced at $42 \mathrm{~h}$, when the creep compliance of the blended pastes was much higher than that of PC. In particular, CFA40 showed the highest creep compliance. The differences become again lower for loading time of $14 \mathrm{~d}$. The creep recovery was calculated based on the deformation of the creep specimen after removing the load and on the autogenous shrinkage of a reference specimen. The non-monotonous creep recovery of CFA40 for creep during $20 \mathrm{~h}$ to $2 \mathrm{~d}$ is believed to be due to the uncertainties and errors of this calculation.

When comparing the results under stepwise loading with those under constant loading at the same loading time, it is observed that the rate of the specific basic creep compliance was lower in the former loading condition because of the loading history. The difference is likely due to the fact that the C-S-H was already under stress (albeit at a lower level) in the stepwise loading regime, and hence it already experienced a large part of the short-term (minutes-long) deformation following the application of load. The difference between the two loading regimes was larger for CQZ40.

(a) $\mathrm{PC}$

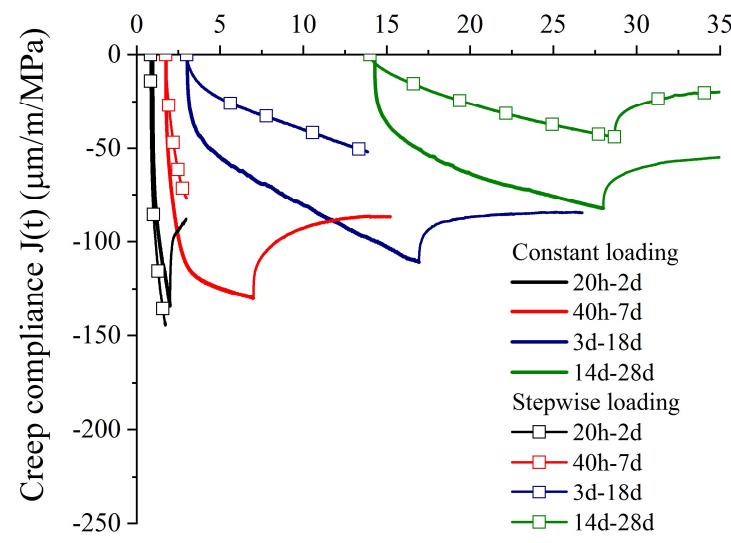

Time (days) (b) CFA40

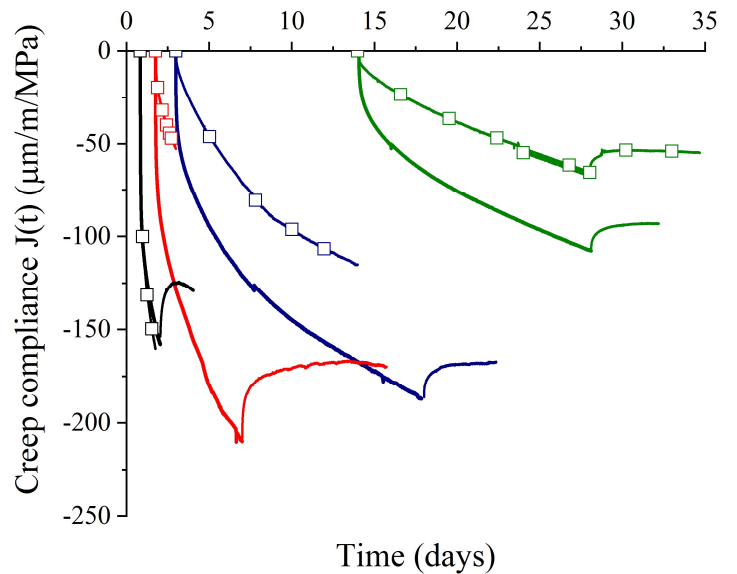


(c) CQZ40

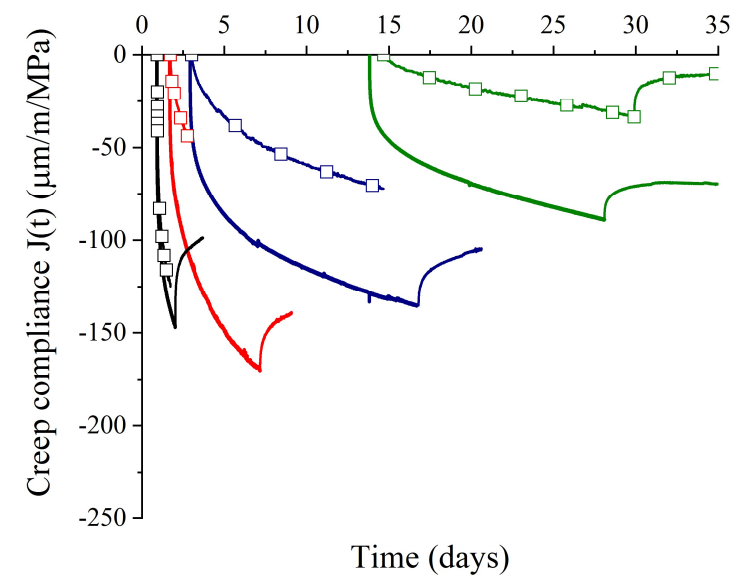

Fig. 10 Comparison between specific basic creep compliance of the three pastes under two kinds of loading processes.

\subsection{Creep recovery}

The comparison of the creep recovery of the three cement pastes undergoing different loading processes is shown in Fig. 11. The creep recovery of the same specimens loaded at $28 \mathrm{~d}$ (already shown in [35]) was also plotted in Fig. 11 (b). The creep recovery at later loading ages reached a plateau faster than that at earlier loading ages, while the total recovery was lower in the former case. When comparing the creep recovery of the cement pastes loaded at $14 \mathrm{~d}$ and $28 \mathrm{~d}$ and those loaded with stepwise loading, the creep recovery seemed very similar in all cement pastes. CFA40 showed the lowest creep recovery at loading ages later than $3 \mathrm{~d}$, which means that the residual deformation was higher in CFA40, since its creep compliance was the highest among all systems. On the other hand, CFA40 had the highest creep recovery when the loading age was earlier than $3 \mathrm{~d}$. The fastest kinetics of creep recovery was found in the PC system. In this study, the total creep strain at the moment of unloading was not correlated to the amount of creep recovery. On the contrary, in [49] creep strain and residual strain were measured on the same mixture with different loading time and it was found that the residual strain was proportional to the creep strain at the moment of unloading. These differences may also be due to the fact that the creep recovery was not completed during the time considered in our study.

(a) 

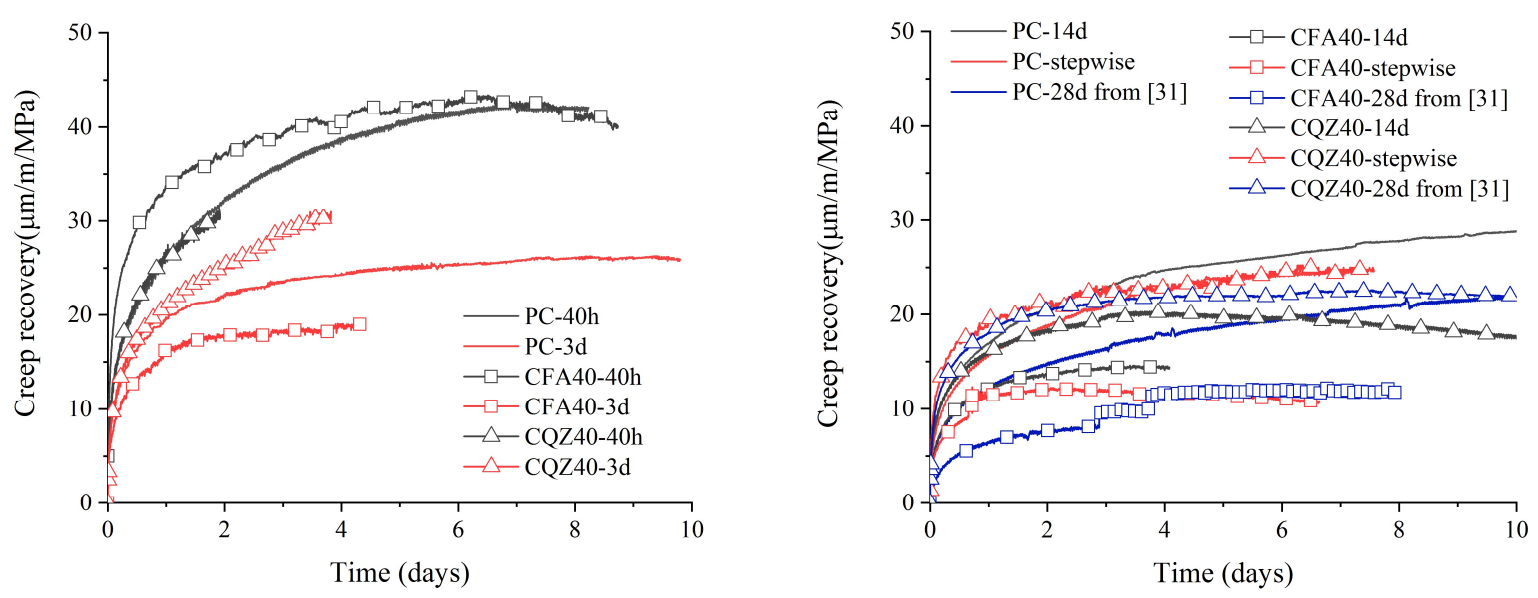

Fig. 11 Comparison of the creep recovery of specimens at the same unloading ages: (a) comparison between creep recovery of specimens loaded at $40 \mathrm{~h}$ and $3 \mathrm{~d}$; (b) comparison between creep recovery of specimens loaded at $14 \mathrm{~d}$, loaded with stepwise loading and loaded at $28 \mathrm{~d}$ (the latter from [35]).

From the few studies of creep recovery published in the literature, the creep recovery appears to depend on the applied stress, loading duration, unloading time and strain at the unloading point [18,49-51]. However, not all these parameters were considered as primary factors. From Fig. 11(b), the strain at the moment of unloading appears to have limited influence on the creep recovery, which is consistent with findings on cement pastes at later ages [35].

\subsection{Prediction of creep strain with rheology models}

\subsubsection{Identification of stiffness and viscosity in rheology models}

A dashpot and three Kelvin-Voigt units were defined with three constant characteristic times $\tau_{n}$, while their stiffness $E_{n}(t)$ increased with age, reaching a value $E_{n}(t=\infty)$ that was determined based on the creep of the specimens loaded at $28 \mathrm{~d}$ [35]. $28 \mathrm{~d}$ results were used because limited hydration occurs after this time and indeed creep appears to have stabilized at that age, see the stable kinetics of cumulative heat release of CFA40 in Fig. 4. In fact, the difference between the kinetics of creep compliance of the specimens loaded at $14 \mathrm{~d}$ and $28 \mathrm{~d}$ were not very significant. Next, the least squares method was used to determine the fitting parameters $\left(E_{n}(t)\right.$ for different loading ages).The selected $\tau_{n}, E_{n}(t=\infty)$ and $\eta_{\infty}$ for all three systems are presented in Table 3. The evolution of $E_{n}(t)$ is a function of $E_{n}(t=\infty)$ and normalized degree of hydration $\bar{\alpha}$, see Eq. (8).

$$
E_{n}(t)=\frac{E_{n}(t=\infty) \cdot a(t) \cdot(\bar{\alpha})^{b}}{c-d \cdot \bar{\alpha}}
$$

where $\bar{\alpha}=\left(\alpha(t)-\alpha_{\text {set }}\right) /\left(\alpha(t=\infty)-\alpha_{\text {set }}\right), \alpha_{\text {set }}$ is the degree of hydration of specimen at the final setting time. $a$, $b, c$ and $d$ are fitting parameters determined from the comparison of the experimental data and the rheology model.

With the parameters presented in the Table 3, the results of fitting creep compliance under constant load for three pastes are shown in Fig.12, 13 and 14, respectively. The degree of hydration was obtained by isothermal calorimetry tests (see Fig 4b). As shown in the figures, with the generalized Kelvin-Voigt chain it was possible to obtain a reasonably good fit of the experimental data. A significant difference is 
observed in PC at loading age of $3 \mathrm{~d}$. In this measurement, a transition happens which cannot be fitted with a continuous change of $E_{n}$.

Table 3 Fitting parameters for pastes in the generalized Kelvin-Voigt model

\begin{tabular}{ccccc}
\hline Sample & Unit number & Chain 1 & Chain 2 & Chain 3 \\
\hline \multirow{4}{*}{ PC } & $\tau_{n}$ (days) & 0.01 & 0.1 & 3.0 \\
& $E_{n}(t)(\mathrm{MPa})$ & 99 & 93 & 85 \\
& $\eta_{\infty}(\mathrm{MPa})$ & & 20 & \\
CFA40 & $E_{n}(t)(\mathrm{MPa})$ & 68 & 94 & 112 \\
& $\eta_{\infty}(\mathrm{MPa})$ & & 37 & \\
CQZ40 & $E_{n}(t)(\mathrm{MPa})$ & 60 & 140 & 34 \\
& $\eta_{\infty}(\mathrm{MPa})$ & & 35 & \\
\hline
\end{tabular}

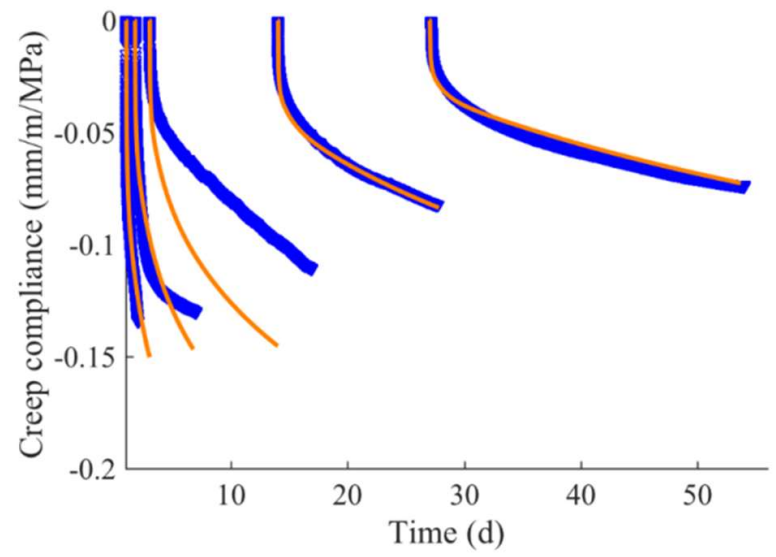

Fig. 12 Comparison of the fitted (orange) and measured (blue) creep compliance in PC.

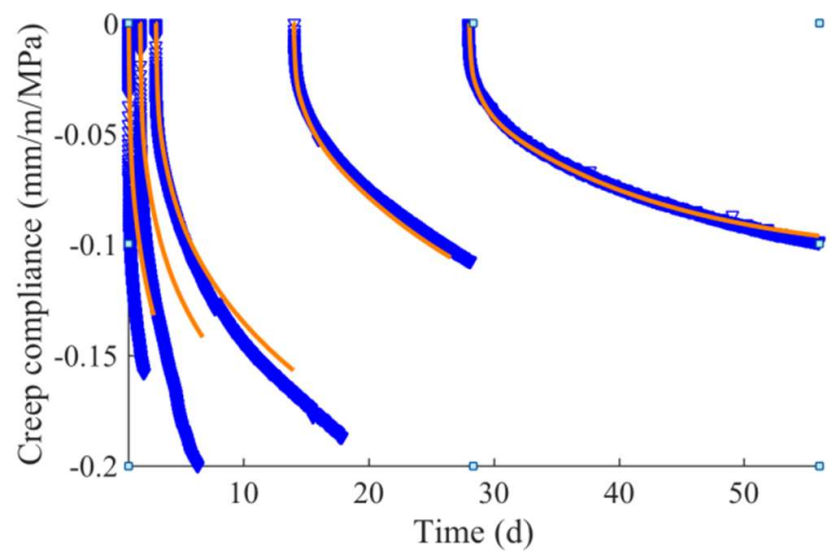

Fig. 13 Comparison of the fitted (orange) and measured (blue) creep compliance in CFA40. 


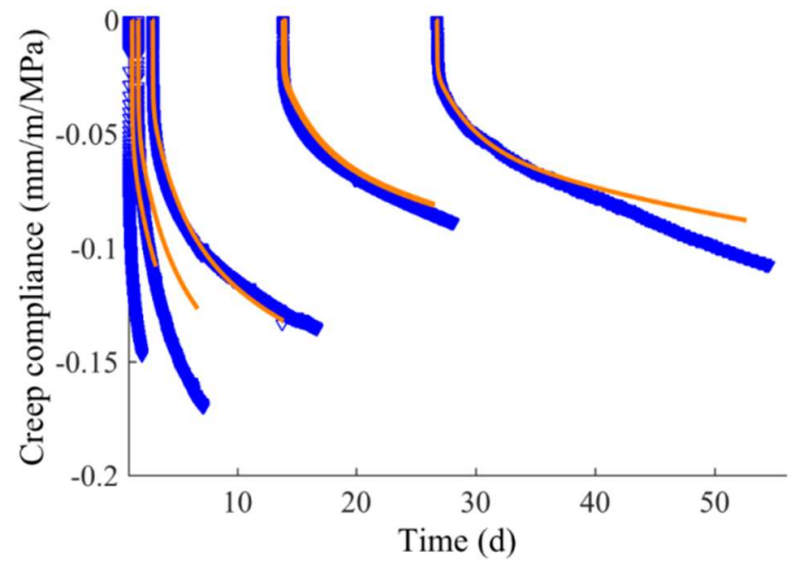

Fig. 14 Comparison of the fitted (orange) and measured (blue) creep compliance in CQZ40.

As can be seen in Fig. 14, poor fit was obtained for some of the creep compliance curves, in particular for the PC system loaded at the age of $3 \mathrm{~d}$. It should be however noted that one set of parameters was fitted for the whole range of ages of each cement paste. The fits are anyway rather accurate for short-term creep at early ages of loading and also for the long-term creep at later loading ages.

\subsubsection{Prediction of creep strain under stepwise loading}

In Fig.15, the creep strain of the three pastes under stepwise loading is predicted by applying the generalized Kelvin-Voigt model with parameters determined in the previous section. The applied load was the same as the one used in the experimental studies. The comparison with the experimental results is made after excluding the elastic (instantaneous) strain and the autogenous shrinkage. For all three pastes, the model was able to achieve a rather good prediction of the experimental results, with the maximum difference between the prediction and the measurements at $28 \mathrm{~d}$ less than $200 \mu \mathrm{m} / \mathrm{m}$.

The main differences are due to:

1. the rapid transition of the creep compliance in the first couple of days (in particular in PC) cannot be captured by using the continuous evolution of parameters in Kelvin-Voigt units. This occurs to a lesser extent also in the two blended pastes, leading to an overestimation of the creep strain (for more details about the transition stage, see the discussion section);

2. at early ages, the calibration of the parameters for constant loading did not allow to obtain a good fit the creep compliance was underestimated. This mismatch propagated and caused an underestimation of the creep strain under sequential loading as well.

In Fig. 15, the prediction obtained by using the Kelvin-Voigt model with constant (non-aging) parameters obtained by fitting experimental data independently at four different ages are also presented. The latter overestimated the creep strain compared to the experimental results and the predicted results using generalized Kelvin-Voigt model with the (aging) algorithm provided in this study. 


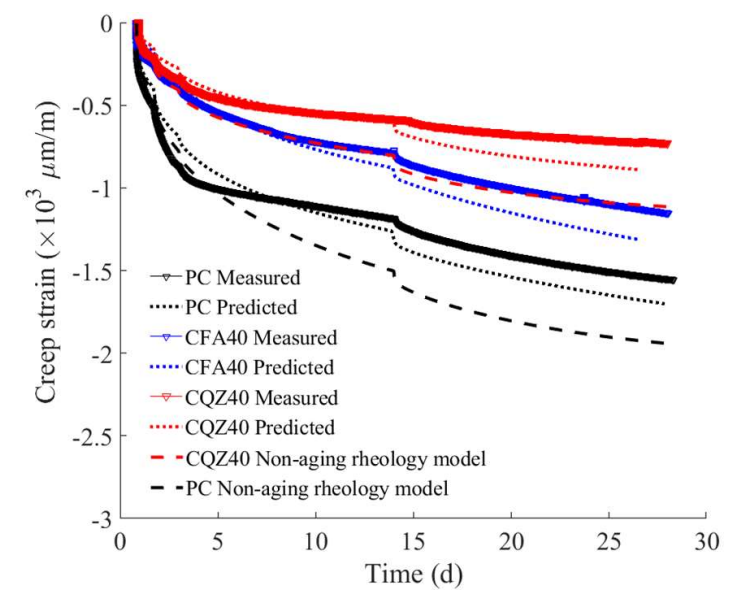

Fig. 15 Comparison of the predicted creep strain of three systems under stepwise loading including the prediction based on the non-aging rheology model of CQZ40 and PC.

\section{Discussion}

The effect of SCMs on the creep compliance observed in Fig. 10 can be qualitatively explained based on differences in microstructure assemblage of the different systems.

According to composite theory and analytical or microstructural homogenization schemes, e.g. [22,52], in a composite system composed of purely elastic and visco-elastic components, the overall behavior depends on the properties (elastic or viscoelastic) of the components. Accordingly, the overall higher stiffness of the PC is due to higher stiffness or higher volume of the individual stiff phases than in the blended systems. The former may be due to considerably higher stiffness of clinker than of the quartz powder or fly ash, the latter due to higher volume of hydration products and reduction of porosity at early ages. Further, considering that for higher stiffness of a single phase (or multiple elastic phases), more stress is transferred to this phase [22,52], the viscoelastic (creeping) phases are subject to a smaller fraction of the total stress in PC than in the blended pastes, resulting in less creep. The restraining effect of the clinker inclusion apparently dominates over the effect of higher volume of creeping phase (C-S-H) in PC.

Porosity is another factor strictly related to the aforementioned volumes of different phases. The blended pastes had higher porosity, as confirmed by the MIP data. Some papers mentioned the effect of porosity on the creep compliance evolution, but without proposing a clear mechanism and without providing convincing evidence $[53,54]$. In general, the systems with higher porosity should have lower elastic properties, as well as higher creep response. In [35], the effect of porosity was discussed in the simulation of the creep compliance at later ages (without considering aging). As clearly shown in [35], the porosity affects significantly the creep results of pastes in which the creep behavior of the C-S-H is the same. In fact, the porosity dominates the apparent creep behavior of the systems.

The fact that the system with quartz had significantly lower creep than the system with fly ash, despite having very similar elastic Young's modulus cannot be explained conclusively at this stage. This might be linked to the higher volume of hydration products in the system with quartz, see Fig. 6 . Another reason for the observed higher creep in the fly ash blended system may be the dissolution mechanism of creep 
proposed recently $[55,56]$. According to this mechanism, creep occurs as the phases bearing load dissolve, leading to a corresponding deformation and redistribution of stresses at the microstructural scale. The dissolution can be either due to: 1) hydration process (dissolution of unhydrated phases, i.e. clinker) [56]; 2) dissolution of the C-S-H enhanced by (locally) high stresses [55,57]. The second dissolution process was originally introduced for wet creep of gypsum plaster but was extended to C-S-H at lower RH (above $50 \%$ [57]). With regard to hydration-driven dissolution while under load, and the corresponding apparent creep, the faster hydration kinetics in the blended systems could explain its higher creep compared to the PC system. At later ages, the dissolution of fly ash (pozzolanic reaction) possibly leads to higher creep compared to the system with (unreactive) quartz. No conclusion can be drawn regarding the effect of pressure-originated dissolution of C-S-H and corresponding apparent creep in the different systems at this stage, due to a preliminary character of the studies of such mechanism.

The effect of water content in the three systems should be also considered. Strong dependence of creep upon the moisture state has been shown in a number of studies. A prominent example is the increase in creep exhibited by drying compared to sealed specimens (drying creep or Pickett's effect [1]). Even though all the systems tested here were kept sealed, due to the different $w / c$ (while the water-to-solid ratio was the same), self-desiccation led to differences in the water saturation degree. According to our parallel study [58], the saturation degrees at $28 \mathrm{~d}$ were about $0.90,0.85$ and 0.80 for CQZ, CFA and PC, respectively. This order of saturation degrees appears to be inversely proportional to that of the creep strains. As long as the mechanisms responsible for Pickett's effect are not clear, one can cautiously assume that, in sealed systems, self-desiccation could lead to an increase in creep. This effect would be manifest even after accounting for self-desiccation shrinkage (i.e. after shrinkage was subtracted from the total deformation curves here).

The effect of the intrinsic creep properties of the C-S-H in the three systems could also play a role in the creep strains measured on the different cement pastes. Results from nano-indentation and accelerated molecular dynamics simulation suggest different creep of C-S-H with different C/S [59]. At the same time, results from micro-indentation [60] and back-calculated results from macroscopic creep using the finite element method [32] show similar intrinsic viscoelastic behavior of C-S-H in different cementitious materials. Another possible factor may be the water content in the C-S-H. According to a recent study, C$\mathrm{S}-\mathrm{H}$ with higher water to silica molar ratio $(\mathrm{H} / \mathrm{S})$ shows higher creep compliance [61]. However, it is not clear how the H/S changes in the C-S-H in the three systems considered in this study. In addition, while the $\mathrm{H} / \mathrm{S}$ increases with the increase of $\mathrm{C} / \mathrm{S}$ in $\mathrm{C}-\mathrm{S}-\mathrm{H}$, when one considers the tobermorite structural units, the amounts of water per unit mass of C-S-H are rather independent of C/S [62].

The numerical prediction with a generalized Kelvin-Voigt chain model with parameters depending (albeit indirectly) on both the degree of hydration and the porosity leads to satisfactory predictions. On the contrary, using non-aging creep results in overestimation of creep compared to the experimental data. These models can be conveniently employed to predict the creep deformation of specimens under complex load histories, for example continuously increasing loads. A notable example is continuously increasing pore pressure in pastes undergoing self-desiccation [58].

In order to gain deeper insights into the effect of SCM on creep, micromechanical models could be used, e.g. [19,63-67]. These models have been recently developed to account for the aging of creep in cementbased materials and validated with some experimental data. The wide range of experimental results presented in our paper can contribute further to validation of the models. 


\section{Conclusions}

In this paper, the visco-elastic behavior of cement pastes with and without fillers and supplementary cementitious materials (i.e. quartz filler and fly ash) was investigated. By using creep stations with gravitational loading, creep of cement pastes at early ages (loading times from $20 \mathrm{~h}$ to $14 \mathrm{~d}$ ) was determined. The obtained curves were smooth and showed clear separations between the instantaneous and the visco-elastic parts. Both loading at specific ages (followed by unloading) and stepwise loading (with load increasing at predetermined ages) were employed.

While both blended pastes showed lower creep compliance than plain cement paste at early ages, systems with fly ash experienced the highest creep compliance at later ages. The higher creep response in the pastes with fly ash or quartz compared to pure cement can be qualitatively explained as a combined effect of the smaller volume of hydration products, higher porosity and lower stiffness of the filler/SCM compared to clinker. At the same time, the paste with fly ash had considerably higher creep compared to a paste with the same volume of cement replaced with quartz filler, especially considering that the two pastes had very similar elastic Young's moduli. The most likely explanation is due to a higher volume of hydration products in the quartz system, as revealed by XRD. Another possible reason is if one considers apparent creep response due to dissolution of elastic phase while under load. In such case, dissolution of fly ash could lead to higher (apparent creep) strains compared to the system with (non-soluble) quartz restraining the body.

The parameters of the generalized Kelvin-Voigt chains, including an algorithm for incremental strain calculation, were calculated based on the creep response of specimens loaded at specific ages. After this calibration, the models were able to give sufficiently accurate predictions of the creep strain of specimens under stepwise loading. This indicates that these relatively simple models are suitable for predicting the creep deformation of specimens under continuously increasing loads, for example increasing pore pressure due to self-desiccation.

\section{Appendix A Comparison of Young's modulus}

The Young's modulus was calculated based on the instantaneous strain (the approximately linear increasing part of the deformation was considered as instantaneous strain, about $5 \mathrm{~s}$; due to enough data points, the turning point of the kinetics of deformation can be clearly observed in the figure) and the applied stress by using the equation A.1 as below:

$$
E\left(t^{\prime}\right)=\frac{\sigma_{a}}{\varepsilon_{a}}
$$

in which $E\left(t^{\prime}\right)$ is the Young's modulus and $\varepsilon_{a}$ is the instantaneous strain. In this study, the Young's modulus calculated based on the instantaneous strain from the creep and creep recovery was compared with the measured Young's modulus from quasi-static Young's modulus test following the standard [68], as shown in Fig. A1. In the quasi-static tests, the loading lasted about $15 \mathrm{~s}$, hence both experiments used a similar time scale. This means that the error in the estimation due to the necessarily included short-term creep strain in the (nominally) instantaneous strain (see [8])should be similar in both types of experiments and should not lead to any significant differences in the obtained Young's moduli. The effect can be in any 
case considered small considering very similar values of loading and unloading Young's moduli from creep tests.

(a) $\mathrm{PC}$

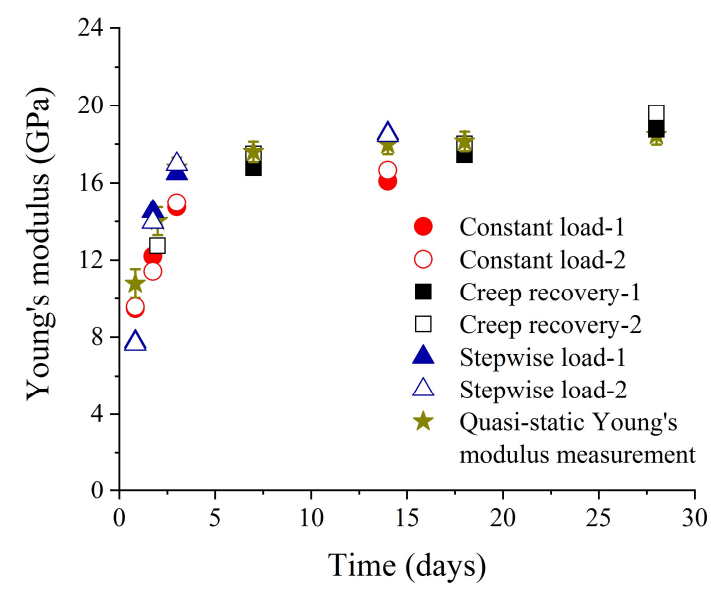

(c) CQZ40

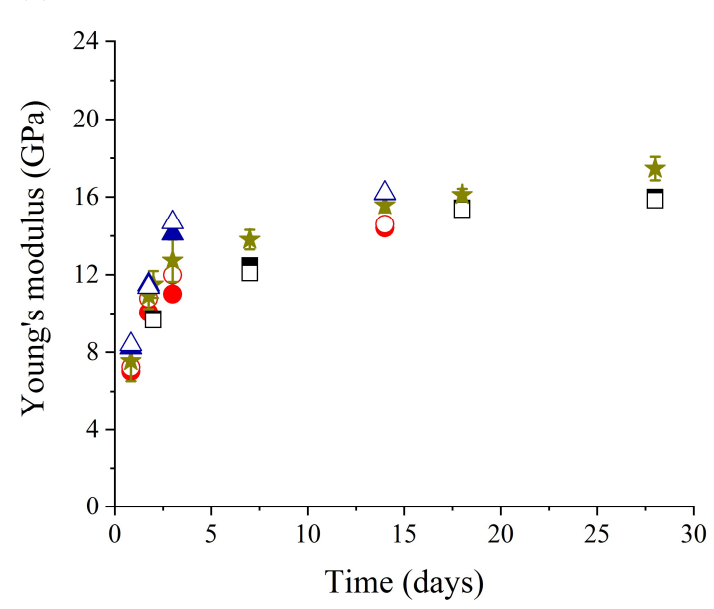

(b) CFA40

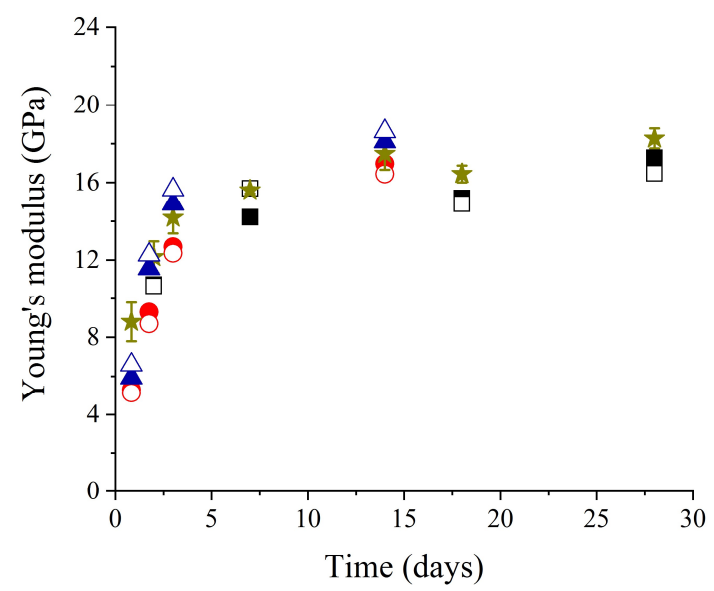

Fig. A1 Comparison between Young's modulus measured from instantaneous strain and quasi-static Young's modulus measurement

By comparing the results of Young's modulus measured by different techniques, it is possible to give a first assessment about the quality of the experiments. As evident in Fig.A1, the samples under constant loading showed on average higher consistency than those under stepwise loading. This could be expected because under the stepwise loading regime, progressively smaller loads are added at later ages, resulting in small, with the consequence of a decrease in the accuracy.

\section{Acknowledgements}

Zhangli $\mathrm{Hu}$ was supported by China Scholarship Council (file No. 201306130062). Mateusz Wyrzykowski was supported by the SNSF Ambizione grant for the project "Role of water redistribution in creep of concrete" (project 161414). 


\section{References:}

[1] Z.P. Bažant, Prediction of concrete creep and shrinkage: past, present and future, Nucl. Eng. Des. 203 (2001) 27-38.

[2] F. Benboudjema, F. Meftah, J.-M. Torrenti, A viscoelastic approach for the assessment of the drying shrinkage behaviour of cementitious materials, Mater. Struct. 40 (2007) 163-174.

[3] Z.P. Bažant, M.H. Hubler, Q. Yu, Pervasiveness of excessive segmental bridge deflections: wakeup call for creep, ACI Struct. J. 108 (2011) 766-774.

[4] Z.P. Bažant, L. Panula, Creep and shrinkage characterization for analyzing prestressed concrete structures, Prestress. Concr. Inst. 25 (1980) 86-122.

[5] T.D. Lämmlein, F. Messina, M. Wyrzykowski, G. Pietro Terrasi, P. Lura, Low clinker high performance concretes and their potential in CFRP-prestressed structural elements, Cem. Concr. Compos. (2019).

[6] O. Bernard, F.J. Ulm, E. Lemarchand, A multiscale mictomechanics-hydration model for the earlyage elastic properties of cement-based materials, Cem. Concr. Res. 33 (2003) 1293-1309.

[7] Z.P. Bažant, P. Santosh, Solidification theory for concrete creep., J. Eng. Mech. 115 (1989) 16911703.

[8] M. Irfan-Ul-Hassan, B. Pichler, R. Reihsner, C. Hellmich, Elastic and creep properties of young cement paste, as determined from hourly repeated minute-long quasi-static tests, Cem. Concr. Res. 82 (2016) 36-49.

[9] Z.P. Bažant, A.B. Hauggaard, S. Baweja, F. Ulm, Creep . I : aging and drying effects, J. Eng. Mech. 123 (1997) 1188-1194.

[10] Z.P. Bažant, S. Prasannan, Solidification theory for aging creep, Cem. Concr. Res. 18 (1988) 923932.

[11] P. Padevět, P. Bittnar, Creep of cementitous materials with addition of fly ash in time, Adv. Mater. Res. 742 (2013) 182-186.

[12] M.J. McCarthy, R.K. Dhir, Development of high volume fly ash cements for use in concrete construction, Fuel. 84 (2005) 1423-1432.

[13] D. Ravina, P.K. Mehta, Properties of fresh concrete containing large amount of fly ash, Cem. Concr. Res. 16 (1986) 227-238.

[14] A.E. Klausen, T. Kanstad, Ø. Bjøntegaard, E. Sellevold, Comparison of tensile and compressive creep of fly ash concretes in the hardening phase, Cem. Concr. Res. 95 (2017) 188-194.

[15] R.P. Lohtia, B.D. Nautiyal, O.P. Jain, Creep of fly ash concrete, ACI J. Proc. (1976) 469-472.

[16] Y.F. Wang, Y.S. Ma, L. Zhou, Creep of FRP-wrapped concrete columns with or without fly ash under axial load, Constr. Build. Mater. 25 (2011) 697-704.

[17] K. Kuder, D. Lehman, J. Berman, G. Hannesson, R. Shogren, Mechanical properties of self consolidating concrete blended with high volumes of fly ash and slag, Constr. Build. Mater. 34 (2012) 285-295.

[18] M.L. Sennour, R.L. Carrasquillo, Creep and shrinkage properties in concrete containing fly ash, 1989.

[19] S. Scheiner, C. Hellmich, Continuum microviscoelasticity model for aging basic creep of early-age concrete, J. Eng. Mech. 135 (2009) 307-323. 
[20] M. Shahidi, B. Pichler, C. Hellmich, Interfacial micromechanics assessment of classical rheological models. II: Multiple interface sizes and viscosities, J. Eng. Mech. 142 (2016) 04015093.

[21] M. Jirásek, P. Havlásek, Microprestress-solidification theory of concrete creep: Reformulation and improvement, Cem. Concr. Res. 60 (2014) 51-62.

[22] J. Sanahuja, Effective behaviour of ageing linear viscoelastic composites: Homogenization approach, Int. J. Solids Struct. 50 (2013) 2846-2856.

[23] D. Gawin, F. Pesavento, B.A. Schrefler, Hygro-thermo-chemo-mechanical modelling of concrete at early ages and beyond. Part I: Hydration and hygro-thermal phenomena, Int. J. Numer. Methods Eng. 67 (2006) 299-331.

[24] D. Gawin, F. Pesavento, B.A. Schrefler, Hygro-thermo-chemo-mechanical modelling of concrete at early ages and beyond. Part II: shrinkage and creep of concrete, Int. J. Numer. Methods Eng. 67 (2006) 332-363.

[25] A. Hilaire, F. Benboudjema, A. Darquennes, Y. Berthaud, G. Nahas, Modeling basic creep in concrete at early-age under compressive and tensile loading, Nucl. Eng. Des. 269 (2014) 222-230.

[26] W. Hermerschmidt, H. Budelmann, Creep of early age concrete under variable stress, in: Concreep 10, 2013: pp. 929-937.

[27] Ch. Pichler, R. Lackner, A multiscale creep model as basis for simulation of early-age concrete behavior, Comput. Concr. 5 (2008) 295-328.

[28] P. Acker, Swelling, shrinkage and creep: a mechanical approach to cement hydration, Mater. Struct. 37 (2004) 237-243.

[29] F.H. Wittmann, Creep and Shrinkage Mechanisms, Creep Shrinkage Concr. 86 (1982) 129-161.

[30] Z.P. Bažant, M. Jirásek, Microprestress-solidification theory and creep at variable humidity and temperature, in: Creep Hygrothermal Eff. Concr. Struct. Solid Mech. Its Appl., Springer, Dordrecht, 2018: pp. 455-498.

[31] T.C. Powers, T.L. Brownyard, Studies of the physical properties of hardened Portland cement paste, J. Am. Concr. Inst. 43 (1946) 101-132.

[32] A. Hilaire, Etude des déformations différées des bétons en compression et en traction, du jeune au long terme : application aux enceintes de confinement, UniverSud Paris, 2015.

[33] M. Azenha, F. Magalhães, R. Faria, Á. Cunha, Measurement of concrete E-modulus evolution since casting: A novel method based on ambient vibration, Cem. Concr. Res. 40 (2010) 1096-1105.

[34] E.N.- BS, Methods of testing cement, Part 1 Determ. Strength. BS EN 169- (2005) 36.

[35] Z. Hu, A. Hilaire, J. Ston, M. Wyrzykowski, P. Lura, K. Scrivener, Intrinsic viscoelasticity of C-S$\mathrm{H}$ assessed from basic creep of cement pastes, Cem. Concr. Res. 121 (2019) 11-20.

[36] ASTM C1698-09:Standard Test Method for Autogenous Strain of Cement Paste and Mortar, 2009.

[37] M. Wyrzykowski, Z. Hu, S. Ghourchian, K. Scrivener, P. Lura, Corrugated tube protocol for autogenous shrinkage measurements: review and statistical assessment, Mater. Struct. 50 (2017) $50-57$.

[38] Z. Hu, M. Wyrzykowski, K. Scrivener, P. Lura, A novel method to predict internal relative humidity in cementitious materials by 1 H NMR, Cem. Concr. Res. 104 (2018) 80-93.

[39] H.F.W. Taylor, Cement chemistry, Thomas Telford Publishing, 1997.

[40] P.T. Durdziński, M. Ben Haha, S.A. Bernal, N. De Belie, G. Elke, B. Lothenbach, J.L. Provis, A. 
Schöler, C. Stabler, Z. Tan, A. Vollpracht, F. Winnefeld, Y. Villagrán Zaccardi, M. Zając, K.L. Scrivener, Outcomes of the RILEM round robin on degree of reaction of slag and fly ash in blended cements, Mater. Struct. 50:135 (2017).

[41] B. Lothenbach, K. Scrivener, R.D. Hooton, Supplementary cementitious materials, Cem. Concr. Res. 41 (2011) 1244-1256.

[42] E. Berodier, K. Scrivener, Understanding the filler effect on the nucleation and growth of C-S-H, J. Am. Ceram. Soc. 97 (2014) 3764-3773.

[43] H.S. Wong, N.R. Buenfeld, Determining the water-cement ratio, cement content, water content and degree of hydration of hardened cement paste: Method development and validation on paste samples, Cem. Concr. Res. 39 (2009) 957-965.

[44] P. Termkhajornkit, T. Nawa, Composition of CSH in the hydration products of fly ash-cement system, Spec. Publ. 242 (2007) 361-374.

[45] E. Sakai, S. Miyahara, S. Ohsawa, S.H. Lee, M. Daimon, Hydration of fly ash cement, Cem. Concr. Res. 35 (2005) 1135-1140.

[46] J. Němeček, V. Šmilauer, L. Kopecký, J. Němečková, Nanoindentation of alkali-activated fly ash, Transp. Res. Rec. J. Transp. Res. Board. 2141 (2010) 36-40.

[47] L. Sorelli, G. Constantinides, F.-J. Ulm, F. Toutlemonde, The nano-mechanical signature of Ultra High Performance Concrete by statistical nanoindentation techniques, Cem. Concr. Res. 38 (2008) $1447-1456$.

[48] M. Wyrzykowski, K. Scrivener, P. Lura, Basic creep of cement paste at early age - the role of cement hydration, Cem. Concr. Res. 116 (2019) 191-201.

[49] P. Rossi, J.L. Tailhan, F. Le Maou, Creep strain versus residual strain of a concrete loaded under various levels of compressive stress, Cem. Concr. Res. 51 (2013) 32-37.

[50] S.-Q. Mei, J.-C. Zhang, Y.-F. Wang, R.-F. Zou, Creep-recovery of normal strength and high strength concrete, Constr. Build. Mater. 156 (2017) 175-183.

[51] Y. Qian, S. Kawashima, Use of creep recovery protocol to measure static yield stress and structural rebuilding of fresh cement pastes, Cem. Concr. Res. 90 (2016) 73-79.

[52] X. Li, Z.C. Grasley, E.J. Garboczi, J.W. Bullard, Modeling the apparent and intrinsic viscoelastic relaxation of hydrating cement paste, Cem. Concr. Compos. 55 (2015) 322-330.

[53] D.T. Nguyen, R. Alizadeh, J.J. Beaudoin, L. Raki, Microindentation creep of secondary hydrated cement phases and C-S-H, Mater. Struct. Constr. 46 (2013) 1519-1525.

[54] D.T. Nguyen, R. Alizadeh, J.J. Beaudoin, P. Pourbeik, L. Raki, Microindentation creep of monophasic calcium-silicate-hydrates, Cem. Concr. Compos. 48 (2014) 118-126.

[55] E.A. Pachon-Rodriguez, E. Guillon, G. Houvenaghel, J. Colombani, Wet creep of hardened hydraulic cements - Example of gypsum plaster and implication for hydrated Portland cement, Cem. Concr. Res. 63 (2014) 67-74.

[56] X. Li, S. Rahman, Z.C. Grasley, Computationally implemented modeling of creep of composite materials caused by phase dissolution, Comput. Mater. Sci. 125 (2016) 61-71.

[57] I. Pignatelli, A. Kumar, R. Alizadeh, Y. Le Pape, M. Bauchy, G. Sant, I. Pignatelli, A. Kumar, R. Alizadeh, Y. Le Pape, A dissolution-precipitation mechanism is at the origin of concrete creep in moist environments, J. Chem. Phys. 145 (2016) 054701.

[58] Z. Hu, M. Wyrzykowski, P. Lura, K. Scrivener, Prediction of autogenous shrinkage of cement 
pastes as poro-visco-elastic deformation, submitted, Cem. Concr. Res. (2019).

[59] M. Bauchy, M. Wang, Y. Yu, B. Wang, N.M.A. Krishnan, E. Masoero, F.J. Ulm, R. Pellenq, Topological control on the structural relaxation of atomic networks under stress, Phys. Rev. Lett. 119 (2017).

[60] W. Wilson, L. Sorelli, A. Tagnit-Hamou, Unveiling micro-chemo-mechanical properties of C-(A)S-H and other phases in blended-cement pastes, Cem. Concr. Res. 107 (2018) 317-336.

[61] A. Morshedifard, S. Masoumi, M.J. Abdolhosseini Qomi, Nanoscale origins of creep in calcium silicate hydrates, Nat. Commun. 9 (2018).

[62] B. Lothenbach, A. Nonat, Calcium silicate hydrates: Solid and liquid phase composition, Cem. Concr. Res. 78 (2015) 57-70.

[63] J. Sanahuja, S. Huang, Mean-field homogenization of time-evolving microstructures with viscoelastic phases: application to a simplified micromechanical model of hydrating cement paste, J. Nanomechanics Micromechanics. 7 (2016) 04016011.

[64] S.T. Nguyen, M.Q. Thai, M.N. Vu, Q.D. To, A homogenization approach for effective viscoelastic properties of porous media, Mech. Mater. 100 (2016) 175-185.

[65] S.T. Nguyen, Q.D. To, M.N. Vu, T.D. Nguyen, Viscoelastic properties of heterogeneous materials: The case of periodic media containing cuboidal inclusions, Compos. Struct. 157 (2016) 275-284.

[66] T. Honorio, B. Bary, F. Benboudjema, Multiscale estimation of ageing viscoelastic properties of cement-based materials: A combined analytical and numerical approach to estimate the behaviour at early age, Cem. Concr. Res. 85 (2016) 137-155. doi:10.1016/j.cemconres.2016.03.010.

[67] F. Lavergne, K. Sab, J. Sanahuja, M. Bornert, C. Toulemonde, Homogenization schemes for aging linear viscoelastic matrix-inclusion composite materials with elongated inclusions, Int. J. Solids Struct. 80 (2016) 545-560.

[68] SN 505 262/1 Construction en béton - Spécifications complémentaires, (2003) 1-28. 